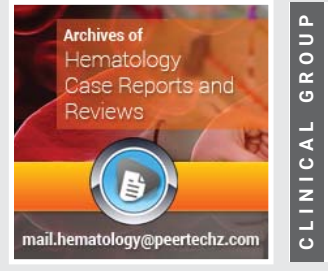

Case Report

\section{Endolymphatic mass in a patient with undiagnosed multiple myeloma}

\section{Michael M McDowell*, Xiao Zhu, Nitin Agarwal, Georgios A Zenonos and Paul A Gardner}

Department of Neurological Surgery, University of Pittsburgh Medical Center, Pittsburgh, PA 15213, USA
Received: 13 February, 2020

Accepted: 10 June, 2020

Published: 11 June, 2020

*Corresponding author: Michael M McDowell, Department of Neurological Surgery, University of Pittsburgh Medical Center, Pittsburgh, PA 15213, USA, Tel: 906282-2284; E-mail:mcdowellmm2@upmc.edu https://www.peertechz.com

\section{Check for updates}

\title{
Abstract
}

Intracranial lesions located within the region of the endolymphatic sac are typically associated with locally invasive disease rather than metastasis. In this case, we report on a 68-year-old man with no oncological history presenting with vertigo and hyperacusis, who was found to have a solitary enhancing mass of the left temporal bone. Subsequent systemic imaging raised concern for a metastatic lesion, and the patient was ultimately diagnosed with multiple myeloma. Multiple myeloma rarely presents with symptomatology consistent with intracranial pathology. This report highlights the importance of surveillance for metastatic disease even when primary lesions are suspected.

\section{Abberivations}

MM: Multiple Myeloma; HCTZ: Hydrochlorothiazide; MRI: Magnetic Resonance Imaging; CNS: Central Nervous System

\section{Case report}

A 68-year-old Caucasian male with a history of coronary artery disease, a recent clavicular fracture, and vertigo sought emergency evaluation for recent episodes of vertiginous attacks with imbalance. Initial episodes of vertigo were well managed with triamterene and hydrochlorothiazide (HCTZ) until several weeks after presentation. He noted that the attacks were worse with position change and nearly caused him to fall on multiple occasions. He also acknowledged hyperacusis in the left ear. On physical examination, he had a positive Romberg's sign and leaned to the left with tandem gait. His hearing with the finger rub test was louder on the left than the right. An MRI brain with and without contrast demonstrated an enhancing mass in the left temporal bone in the area of the endolymphatic sac, which extended inferiorly towards the jugular foramen (Figure 1).

The main item on the differential was an endolymphatic sac tumor due to the location, high T1 signal, and further enhancement with contrast (Figure 1a-d). Imaging characteristics were also consistent with other true endolymphatic sac tumors . Less likely alternatives included metastasis, glomus tumor, cholesteatoma, or cholesterol granuloma. Imaging of the chest, abdomen and pelvis were performed as part of the work up. These demonstrated numerous lytic lesions including pathological rib and clavicular fractures, as well as a $8.4 \times 6.2 \mathrm{~cm}$ soft tissue mass involving the
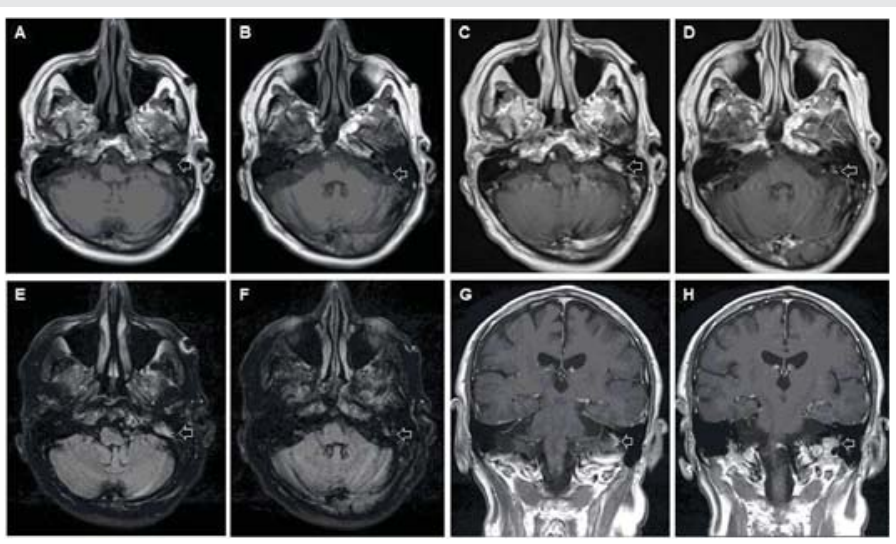

Figure 1: $1.5 \mathrm{~cm}$ enhancing extra-axial mass in the region of the endolymphatic sac adjacent to the left jugular foramina. A, B) Axial T1-weighted MR images without contrast. C, D) Axial T1-weighted MR images with contrast. E, F) Axial FLAIR images. G, H) Coronal T1-weighted MR images with contrast. 
left iliac bone (Figure 2). Percutaneous biopsy of the soft tissue mass revealed a CD138-positive, kappa light chain-restricted plasma cell neoplasm, and was negative for pankeratin, CD20, and lambda light chain, leading subsequently to a diagnosis of multiple myeloma ( $M M)$ based on bone marrow biopsy. Intracranial extension of the MM lesion from the skull base and involvement of the endolymphatic sac was ultimately responsible for his presenting symptoms. No immediate surgical intervention was recommended and the patient was referred to Oncology for second opinion. In collaboration with Oncology, a conservative approach was agreed to be the best option..

\section{Discussion}

Multiple myeloma (MM) is a neoplastic disorder formed by monoclonal proliferation of immunoglobulin-secreting plasma cells. There are often neurological sequelae in patients with MM such as spinal cord compression, spinal radiculopathies, peripheral neuropathies, and cranial nerve palsies; however, direct intracranial symptomatology is rare $[1,2]$. This patient did not initially present with symptoms classical for MM, but instead secondary to symptoms attributable to his intracranial metastasis. The symptomatology and location of his lesion suggested an endolymphatic sac tumor, and the radiographic characteristics were comparable to that of true endolymphatic sac tumors (Figure 3).

Concern for metastatic disease was felt to be unlikely on initial evaluation due to focal neurological findings and lack of bony metastasis clearly identified on initial imaging. Glomus tumors typically present with "salt and pepper" distribution on MRI with a low T1 signal and intense enhancement following contrast. Cholesteatomas similarly have low T1 signals, but no enhancement with contrast, while cholesterol granulomas display $\mathrm{T} 1$ hyperintensity with no post-contrast enhancement, or only peripheral rim-enhancement. These alternatives were unlikely given the location and pattern of enhancement seen in our patient (Figure 1). Subsequent imaging of his viscera confirmed the diagnosis of metastasis.
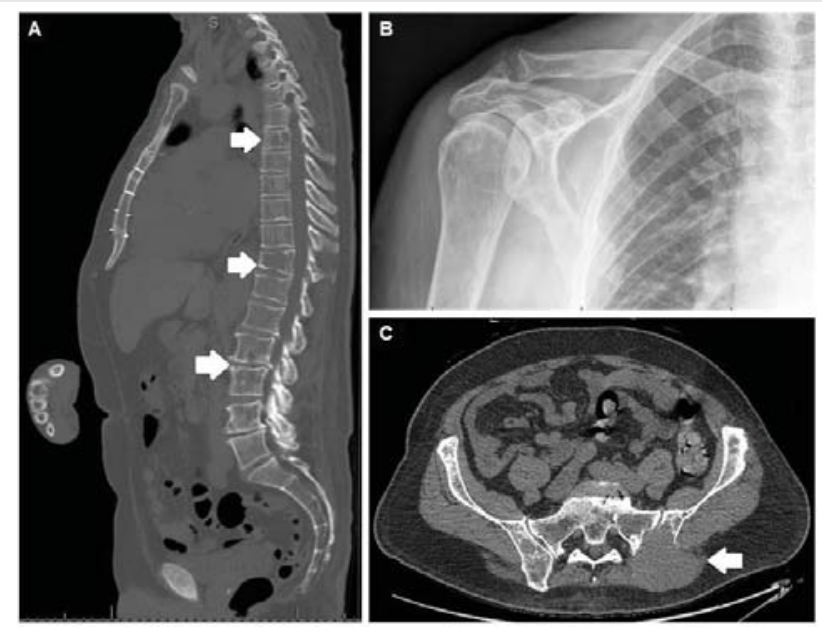

Figure 2: Lytic bone lesions, pathological fractures, and sacral mass as a result of multiple myeloma A) CT showing multiple thoracolumbar lesions along with compression fractures. B) X-ray showing pathological right clavicular fracture. C). Pelvic CT demonstrating a large soft tissue mass.
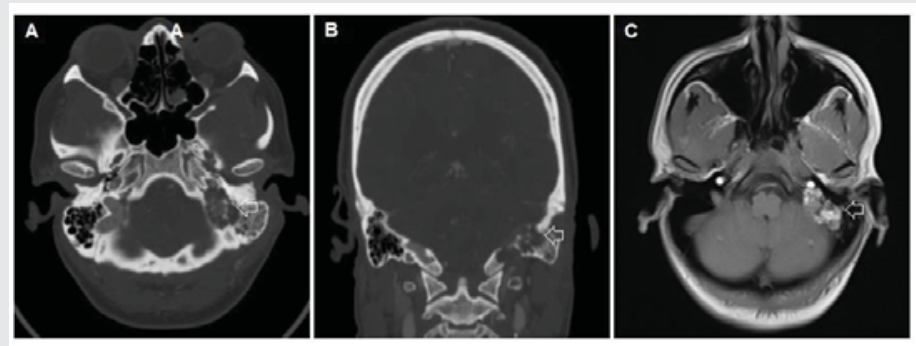

Figure 3: Images from past patients with real and supposed endolymphatic sac tumor. A, B). Axial and coronal CT from a patient with a real endolymphatic sac tumor. C). T1-weighted MR image with contrast showing a real endolymphatic sac tumor.

In cases of intracranial $\mathrm{MM}$, the median interval from $\mathrm{MM}$ diagnosis to CNS involvement is about 13 months. ${ }^{3}$ Given this delay, neurological symptoms as an initial presentation of MM are uncommon and have only been documented in limited numbers [3-11]. CNS involvement of MM significantly decreases overall survival; however, whether or not an initial neurological presentation of MM affects lifespan is unknown [ 3,5]. Clinical course of these rare cases varies widely depending on disease stage and treatment modalities, and have insufficient followup to draw any concrete conclusions. Hyperviscosity syndrome secondary to an elevated paraprotein level occasionally presents with vertigo, imbalance, and hearing changes, but our patient did not exhibit other classical signs, such as bleeding diatheses or visual disturbances $[1,12]$. To our knowledge, this is the first report of MM initially presenting with vestibular dysfunction due to isolated intracranial MM lesions.

Intracranial plasma cell neoplasms typically arise by direct extension from cranial bone lesions or leptomeningeal spread, but may also rarely present as an intraaxial brain lesion without osseous or dural contacts [3]. In a review of 1586 patients with MM, Fassas, et al. found that only 18 (1.1\%) had evidence of CNS involvement as defined by detection of malignant plasma cells in the CSF, and 15 of those 18 patients had abnormal MRI findings [7], leptomeningeal, 2 skull base, 2 sphenoidal, 1 ventricular, 1 epidural, 1 calvarial, 1 clival) [5]. Of note, skull base plasmacytomas have been reported and appear to have a very strong association with progression to MM $[6-8,10,13]$ Schwartz, et al. reviewed the disease course of 9 intracranial plasmacytomas (3 dural, 1 calvarial, 5 skull base), and found that all 5 skull base plasmacytomas developed MM within 8 months [13]. It is possible that our patient had a solitary bone plasmacytoma at the skull base near the endolymphatic sac that eventually progressed to MM; however, the diffuse nature of his metastatic disease and size of the pelvic soft tissue mass suggest that intracranial involvement was a result of metastasis rather than the primary lesion.

Intracranial plasmacytomas are very radiosensitive, and optimal treatment often involves total surgical resection followed by post-operative radiotherapy [3,6-8,10,13,14]. In cases of plasmacytomas involving the skull base, complete resection may be impossible given anatomic restrictions, and should be treated with subtotal resection and irradiation, or irradiation alone.3,6 The treatment in such cases is controversial but usually involves common myeloma therapies 
with immunomodulatory drugs, proteasome inhibitors, and consolidation with a bone marrow transplant are favored over surgical resection. In some cases, chemotherapy regimens were also used $[3,5,6,8,10,11,14]$. Median life expectancy of patients with MM at the skull base is 3 years, but prognosis is improved following high-dose chemotherapy and stem cell transplantation $[3,5,7,10,11]$. There are very few reports of surgical resection in cases of intracranial MM, most of which were always performed prior to an established diagnosis of MM and followed by chemotherapy, radiation therapy, and/or stem cell transplantation $[4,6,14]$. Review of the literature identified two cases of intracranial MM treated with only surgery: both patients had craniotomies for symptomatic parietal lesions - one had a history of MM in remission and passed 1 month post-op before further treatment could be pursued, the other was diagnosed with MM post-opearatively, but refused further treatment and passed 6 months later [14]. If the lesion in our patient were to be treated with surgical resection alone, as is recommended with endolymphatic sac tumors due to the controversial role of radiation or chemotherapy, our patient would likely rapidly deteriorate due to the diffuse nature of his disease [15-17].

Multiple Myeloma represents one of the "great imitators" of modern medicine. While rare, skull base lesions may represent a number of primary or secondary malignancies. Thorough consideration of the possibility of metastasis is advisable even in circumstances involving pathognomonic radiographic findings. Presentation with neurological findings is uncommon in MM, and suggests an unfortunate prognosis when coupled with diffuse systemic disease.

\section{References}

1. Dispenzieri A, Kyle RA (2005) Neurological aspects of multiple myeloma and related disorders. Best Pract Res Clin Haematol 18: 673-688. Link: https://bit.ly/2AUjKBt

2. Schluterman KO, Fassas AB, Van Hemert RL, Harik SI (2004) Multiple myeloma invasion of the central nervous system. Vojnosanit Pregl 61:1423-1429. Link: https://bit.ly/2BOE1VH Intracranial involvement in plasmacytomas and multiple myeloma: a pictorial essay. Neuroradiology. Neuroradiology 50: 665-674. Link: https://bit.ly/2UvyMnY

4. Eum JH, Jeibmann A, Wiesmann W, Paulus W, Ebel H (2009) Multiple myeloma manifesting as an intraventricular brain tumor. J Neurosurg 110: 737-739. Link: https://bit.ly/37kqnZH

5. Fassas AB, Muwalla F, Berryman T, Benramdane R, Joseph L, et al. (2002) Myeloma of the central nervous system: association with high-risk chromosomal abnormalities, plasmablastic morphology and extramedullary manifestations. Br J Haematol 117: 103-108. Link: https://bit.ly/3dRBb4f cell myeloma of the skull base: report of two cases. Brain tumor pathology 21: 135-141. Link: https://bit.ly/2MTcGYd

\section{Conclusions}

3. Cerase A, Tarantino A, Gozzetti A, Muccio CF, Gennari P, et al. (2008)

6. Higurashi M, Yagishita S, Fujitsu K, Kitsuta Y, Takemoto Y, et al. (2004) Plasma

7. Terada $T$ (2009) Multiple myeloma presenting as an intracranial plasmacytoma: a case report. Cases J 2: 9110. Link: https://bit.ly/37lvlpc

8. Ustuner Z, Basaran M, Kiris T, Bilgic B, Sencer S, et al. (2003) Skull Base Plasmacytoma in a Patient with Light Chain Myeloma. Skull base official journal of North American Skull Base Society 13: 167-171. Link: https://bit.ly/37lvmtg

9. Wavre A, Baur AS, Betz M, Mühlematter D, Jotterand M, et al. (2007) Case study of intracerebral plasmacytoma as an initial presentation of multiple myeloma. Neuro Oncol 9: 370-372. Link: https://bit.ly/30BLF3X

10. Wein RO, Popat SR, Doerr TD, Dutcher PO (2002) Plasma cell tumors of the skull base: four case reports and literature review. Skull base : official journal of North American Skull Base Society 12: 77-86. Link: https://bit.ly/2AXU72F

11. Yi HJ, Hwang HS, Moon SM, Shin IY, Choi YH (2013) A case of multiple myeloma with brain parenchyme involvement. Brain Tumor Res Treat 1: 103106. Link: https://bit.ly/30v9dY3

12. Adams BD, Baker R, Lopez JA, Spencer S (2009) Myeloproliferative disorders and the hyperviscosity syndrome. Emerg Med Clin North Am 27: 459-476. Link: https://bit.ly/30wyWze

13. Schwartz TH, Rhiew R, Isaacson SR, Orazi A, Bruce JN (2001) Association between intracranial plasmacytoma and multiple myeloma: clinicopathological outcome study. Neurosurgery 49: 1039-1044. Link: https://bit.ly/37rAJY0

14. Bindal AK, Bindal RK, van Loveren H, Sawaya R (1995) Management of intracranial plasmacytoma. J Neurosurg 83: 218-221. Link: https://bit.ly/3fb8teB

15. Diaz RC, Amjad EH, Sargent EW, Larouere MJ, Shaia WT (2007) Tumors and pseudotumors of the endolymphatic sac. Skull base : 17: 379-393. Link: https://bit.ly/3dVrj9E

16. Ferri E, Amadori M, Armato E, Pavon I (2014) A rare case of endolymphatic sac tumour: clinicopathologic study and surgical management. Case Rep Otolaryngol 2014: 376761. Link: https://bit.ly/3fb8yyV

17. Friedman RA, Hoa M, Brackmann DE (2013) Surgical management of endolymphatic sac tumors. J Neurol Surg B Skull Base 74: 12-19. Link: https://bit.ly/2XOKgVQ

Discover a bigger Impact and Visibility of your article publication with Peertechz Publications

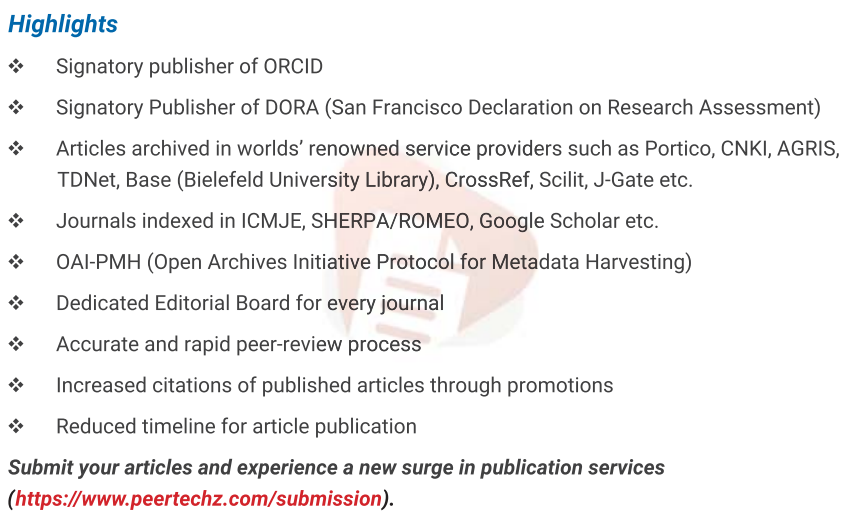

Copyright: @ 2020 McDowell MM, et al. This is an open-access article distributed under the terms of the Creative Commons Attribution License, which permits unrestricted use, distribution, and reproduction in any medium, provided the original author and source are credited. 